\title{
Escolarização de alunos com TEA: práticas educativas em uma rede pública de ensino
}

\author{
Education of students with ASD: educational practices in a public teaching \\ network
}

\author{
Educación de estudiantes con TEA: prácticas educativas en una red de \\ enseñansa pública
}

\author{
Luiza Pinheiro Leão Vicari \\ Mestre pela Universidade Federal de Minas Gerais, Belo Horizonte, Minas Gerais, Brasil. \\ luizavicari15@gmail.com \\ ORCID - https://orcid.org/0000-0001-8431-141X \\ Mônica Maria Farid Rahme \\ Professora doutora na Universidade Federal de Minas Gerais, Belo Horizonte, Minas Gerais, Brasil. \\ monicarahme@ufmg.br \\ ORCID - https://orcid.org/0000-0003-2123-2989
}

Recebido em 2 de abril 2020

Aprovado em 14 de junho de 2020

Publicado em 8 de julho de 2020

\section{RESUMO}

Esse estudo teve como objetivo analisar as práticas educativas adotadas no cotidiano escolar de dois alunos com Transtorno do Espectro Autista (TEA) em uma escola pública de Belo Horizonte/MG. O TEA é marcado por dificuldades na comunicação social, comportamentos repetitivos e interesses restritos. O número de matrículas desses alunos aumentou nos últimos anos e a legislação brasileira passou a prever a possibilidade do acompanhamento do profissional de apoio e/ou do professor do Atendimento Educacional Especializado (AEE). Com referência nesses dados, essa pesquisa foi desenvolvida a partir de uma abordagem qualitativa e buscou discutir as possibilidades e os limites do processo de inclusão escolar dos alunos com TEA. Utilizou-se como instrumentos de coleta de dados a observação sistemática em duas salas de aula, entrevistas semiestruturadas e a aplicação da Escala CARS. Os resultados indicam que as profissionais reconhecem um avanço no processo de inclusão, entretanto, demonstram insegurança quanto às estratégias de ensino a serem adotadas. Além disso, não identificam apoio efetivo dos órgãos responsáveis pelo processo de inclusão. Os alunos com TEA passam a maior parte do tempo em sala de aula, mas poucas atividades são direcionadas para as suas especificidades. Nesses períodos, contam com o acompanhamento de auxiliares de apoio à inclusão, cujas atuações variam conforme o grau de envolvimento com o trabalho. Tais profissionais não pertencem ao quadro do magistério e recebem poucas orientações. Das seis professoras entrevistadas, apenas duas evidenciaram práticas educativas inclusivas durante o período da pesquisa, ainda que com baixa frequência.

Palavras-chave: Transtorno do Espectro Autista; educação inclusiva; práticas educativas. 
http://dx.doi.org/10.5902/1984686X43296

\section{ABSTRACT}

The study aims to analyze the educational practices adopted in the school routine of two students with Autism Spectrum Disorder (ASD) in the city of Belo Horizonte/MG. ASD is marked by difficulties in social communication and the presence of repetitive behaviors and restricted interests. The number of enrollments of these students has been growing in recent years and Brazilian legislation contributes to expanding the right to education for these students. Among these rights, there is the monitoring of the support professional and the teacher of Specialized Educational Service. This study, with a qualitative approach, discusses the possibilities and limits of the school inclusion process of students with ASD. Were used as data collection instruments systematic observation in two classrooms, semi-structured interviews and the CARS scale. The results indicate that the professionals recognize an advance in the inclusion process in the municipal education, however, they still demonstrate insecurity regarding the teaching strategies to be adopted, as they do not identify effective support from the municipal education network in the inclusion process. Students spend most of their time in the classroom, but few activities are geared to their specifics; they spend most of their time with assistants to support inclusion, and their activities vary according to the degree of involvement with the work, since they do not belong to the teaching staff and receive few orientations. Of the six interviewed teachers, only two showed inclusive educational practices during the research period, even if low frequency.

Keywords: Autistic Spectrum Disorder; inclusive education; educational practices.

\section{RESUMEN}

El estudio tiene objetivo de analizar las prácticas educativas adoptadas en la rutina escolar de estudiantes con Trastorno del Espectro Autista (TEA) en Belo Horizonte/MG. TEA es marcado por dificultades en la comunicación social y la presencia de comportamientos repetitivos e interés restringido. El número de matrículas de estos estudiantes ha aumentado en los últimos años y la legislación brasileña contribuye a ampliar el derecho a la educación de estos estudiantes. Entre estos derechos, está el monitoreo del profesional de apoyo y el maestro del Servicio Educativo Especializado. Este estudio, con un enfoque cualitativo, analiza las posibilidades y los límites del proceso de inclusión escolar de los estudiantes con TEA. Fue utilizado como instrumentos de recolección de datos la observación sistemática en dos aulas, las entrevistas semiestructuradas y la aplicación de la Escala CARS. Los resultados indican que los profesionales reconocen un avance en el proceso de inclusión, sin embargo, aún demuestran inseguridad con respecto a las estrategias de enseñanza a adoptar, ya que no identifican el apoyo efectivo de la red en el proceso de inclusión. Los estudiantes pasan la mayor parte de su tiempo en el aula, pero pocas actividades están orientadas a sus peculiaridades; ellos pasan la mayor parte de su tiempo con asistentes de apoyo a la inclusión, y sus actividades varían según el grado de participación en el trabajo, ya que no pertenecen al personal docente y reciben poca orientación. De los entrevistados, solo dos maestros mostraron prácticas educativas inclusivas, aunque con baja frecuencia.

Palabras clave: Trastorno del Espectro Autista; educación inclusiva; prácticas educativas.

\section{Introdução}

A palavra autismo tem origem grega, aUTo, e significa "auto". Foi por volta de 1910 que o psiquiatra suíço Eugen Bleuler (1857-1939) empregou o termo pensamento autístico, para descrever um comportamento e uma tendência de seus pacientes adolescentes e 
http://dx.doi.org/10.5902/1984686X43296

adultos de desconectar-se das interações sociais e se relacionar, exclusivamente, com uma realidade interior (DONVAN; ZUCKER, 2017). Em 1943, Leo Kanner, um psiquiatra austríaco descreveu o caso de 11 crianças com dificuldades de comunicação e interação social, dando o nome de Distúrbios Autísticos do Contato Afetivo.

De 1943 até os dias atuais, mudanças relevantes ocorreram em relação aos critérios para diagnóstico e conceito de autismo. Na última versão do Diagnostic and Statistical Manual of Mental Disorders- DSM (Manual Estatístico de Transtornos Mentais), de 2014, o autismo é definido como Transtorno do Espectro Autista (TEA) e é caracterizado pela presença de dificuldades persistentes na comunicação social e por padrões restritos e repetitivos de comportamentos, interesses ou atividades - sintomas que se manifestam no período da infância. Como assinala Schmidt (2017, p. 223), com o passar dos anos constatou-se que a "classificação no formato categórico era inapropriada, sendo preferível a abordagem como um espectro único, cujas características e sintomas variam ao longo de um continuum". No espectro, há uma enorme variabilidade em termos de comportamento, cognição, desenvolvimento motor e comunicação.

Quanto ao número de casos de autismo na população, o relatório norte-americano do Centers for Disease Control and Prevention/USA (2020) indica nos seus últimos dados epidemiológicos, datados de 2016, que a prevalência do TEA é de um a cada 54 crianças. As estatísticas indicam, ainda, que o TEA é quatro vezes mais comum em meninos que em meninas, e está presente em todos os grupos raciais, étnicos e socioeconômicos. No Brasil, temos um único estudo-piloto de Paula, Ribeiro, Fombone e Mercadante (2011), que encontrou uma prevalência do TEA em 0,3\% em uma amostra de 1.470 crianças de 7 a 12 anos de idade.

Sobre o aumento do número de matrículas de alunos com deficiência como um todo, os dados da Política Nacional de Educação Especial na Perspectiva da Educação Inclusiva (2008) indicam que, de 1998 até 2006, houve um aumento de 640\% de matrículas em escolas regulares/classes comuns (BRASIL, 2008). A respeito de alunos com TEA, é necessário salientar que os dados do Censo Escolar do Instituto Nacional de Estudos e Pesquisas Educacionais (INEP) seguem a Classificação Internacional de Doenças (CID10), que identifica o autismo como Transtorno Global do Desenvolvimento (TGD), apresentando uma divisão entre TGD/Autismo e TGD/Síndrome de Asperger. No período de 2012 a 2019, o número de matrículas de alunos com autismo (TGD/Autismo e TGD/ Asperger) cresceu 550,25\% (BRASIL, 2017). 
Embora se tenha uma ampliação do acesso desses estudantes às escolas regulares na atualidade, a história da educação dos alunos público-alvo da educação especial foi construída por um longo caminho. Marcadas por uma trajetória de exclusão, as iniciativas de educação para esse público, no Brasil, podem ser observadas desde o século XIX, caracterizadas por ações isoladas e, de acordo com a tendência da época, previa uma escolarização fora do sistema de educação geral, concentrada em instituições residenciais e em hospitais (MENDES, 2006). Nos últimos anos, leis nacionais asseguram o direito à educação das pessoas com deficiência: a Lei de Diretrizes e Bases da Educação Nacional - Lei no 9.394 (BRASIL; 1996); a Lei Brasileira de Inclusão - Lei no 13.146 (BRASIL, 2015) e, especificamente no âmbito do autismo, a Lei o 12.764 (BRASIL 2012).

A Lei $n-12.764$ explicita que, quando comprovada a necessidade, os alunos com TEA terão direito a acompanhante especializado. Este profissional, conforme Nota Técnica no 24 (BRASIL; MEC/SECADI/DPEE, 2013), tem como função a acessibilidade à comunicação e atenção aos cuidados pessoais de alimentação, higiene e locomoção.

Apesar dos avanços na legislação e nos direitos das pessoas com TEA, estudos como o de Cabral e Marin (2019) demonstram o baixo número de pesquisas na área da educação e inclusão destes estudantes. Além disso, a pesquisa de Nunes, Azevedo e Schmidt (2013) analisa o desconhecimento dos docentes quanto às características da criança com TEA e a existência de poucas estratégias pedagógicas que impactam no seu processo de aprendizagem.

Assim, a partir dos aspectos apresentados, este artigo discute questões relacionadas à inclusão de alunos com TEA matriculados no Ensino Fundamental na Rede Municipal de Ensino de Belo Horizonte (RME-BH), focalizando, mais propriamente, as práticas educativas desenvolvidas pelos professores regentes, professores especializados e auxiliares de apoio à inclusão - profissionais que acompanham os alunos com deficiência nessa Rede de ensino. O texto é resultado de uma pesquisa desenvolvida no curso de Mestrado em Educação, que teve como objetivo compreender as estratégias educativas adotadas por esses profissionais e verificar se o percurso de inclusão escolar de crianças com autismo superava o acesso à escola, proporcionando aprendizagem e permanência nesse contexto. 
http://dx.doi.org/10.5902/1984686X43296

\section{Metodologia}

Esse trabalho foi submetido ao Comitê Nacional de Ética em Pesquisa e registrado com CAEE 79998117.4.0000.5149. Após a aprovação pelo Comitê, foi feito contato com a Diretoria de Educação Inclusiva e Diversidade Étnico-Racial da Secretaria Municipal de Educação de Belo Horizonte, para solicitar sua aprovação. Posteriormente, foi selecionada uma escola, considerando-se dois critérios: (1) ter alunos com TEA matriculados no $1^{\circ}$ ciclo que fossem acompanhados pelo auxiliar de apoio à inclusão; (2) ter uma sala de Atendimento Educacional Especializado (AEE) em funcionamento na escola.

O foco no $1^{\circ}$ ciclo teve relação com dois fatores. Primeiro, por marcar a transição da Educação Infantil para o Ensino Fundamental e, segundo, por ser o ciclo da alfabetização, que costuma representar, para a maior parte dos alunos, um momento desafiador e de diversas mudanças, tais como as modificações da sala de aula, disposição dos materiais e tipos de avaliação. (ZANATA; MARCON, 2015). Em geral, as crianças têm avaliações mais sistemáticas, usam livro didático na maior parte do tempo, precisam permanecer sentados por períodos mais longos e recebem atividades diárias para serem feitas em casa.

As aulas no Ensino Fundamental eram divididas entre a professora regente, que passava a maior parte do tempo com os alunos, e a professora especializada, que permanecia 50 minutos, por dia, com a turma e era responsável pelas aulas de Ciências, Artes e Educação Física.

A pesquisa foi composta por três etapas. Na primeira, foram feitas observações sistemáticas em sala de aula e nos demais ambientes da escola, como pátio, quadra e refeitório. Em seguida, foram realizadas entrevistas com os profissionais da educação; e, no terceiro momento, aplicou-se a Escala CARS - Childhood Autism Ratting Scale (SCHOPLER; REICHLER; RENNER, 1998). A investigação foi referenciada em uma abordagem qualitativa, que reconhece um "vínculo indissociável entre o mundo objetivo e a subjetividade do sujeito, que não pode ser traduzido em números" (KAUARK; MANHÃES; MEDEIROS, 2010, p. 31).

As observações foram realizadas com a turma do $1^{\circ}$ ano durante um período de sete dias, e de nove dias a do $2^{\circ}$ ano. As observações ocorreram durante todo o período em que os alunos encontravam-se na instituição, ou seja, das $13 \mathrm{~h}$ às $17 \mathrm{~h} 30$, o que inclui tanto as atividades em sala, quanto fora da sala de aula. Desta maneira, a pesquisadora pôde acompanhar os alunos em diversos ambientes escolares ao longo do dia. 
http://dx.doi.org/10.5902/1984686X43296

\section{Participantes}

Após o primeiro contato com o coletivo de professores da escola e profissionais da gestão escolar, duas professoras regentes, uma do $1^{\circ}$ ano e outra do $2^{\circ}$, prontificaram-se a participar da pesquisa. A partir dessa definição, foram realizadas observações na Sala 1 e na Sala 2. Na sala 1, encontrava-se matriculado um aluno com diagnóstico de Transtorno Global do Desenvolvimento(TGD)/Autismo, com 6 anos de idade, e que será chamado de Ricardo. Ricardo tem um repertório de comunicação verbal, apresenta habilidades para fazer pedidos e nomeações, utiliza frases de uma a duas palavras ou gestos. Com frequência, apresenta estereotipias motoras, como o flap. Na Sala 2, estuda Túlio, um aluno de 8 anos, que também apresenta o diagnóstico de TGD/ Autismo. Túlio é uma criança com baixo repertório de comunicação, não faz uso funcional da fala e tem poucos recursos para comunicar-se, além de manifestar dificuldades comportamentais. Os dois alunos contavam com o acompanhamento da auxiliar de apoio e somente o aluno da Sala 1 participava de atividades na sala do AEE, uma vez por semana, durante uma hora, e no contraturno escolar. As professoras especializadas das Salas 1 e 2 também se integraram à pesquisa. As professoras do AEE participaram apenas das entrevistas.

\section{Sala 1}

A Sala 1 contava com 24 alunos. Tinha como referência a professora Lílian e, como professora especializada, Cristiane. Ambas eram pedagogas, com Pós-Graduação lato sensu. A auxiliar de apoio à inclusão que acompanhava o aluno com TGD/Autismo cursou o Ensino Médio e não possuía nenhum tipo de formação voltada para educação ou educação inclusiva. A professora que o atendia era graduada em Psicologia e possuía diversos cursos de especialização na área da Educação. Os alunos da Sala 1 costumavam sentar-se enfileirados em carteiras preestabelecidas pela professora regente. Durante todos os dias de observação, não havia um lugar determinado para o aluno com TEA, que se sentava nas últimas carteiras, ao lado da auxiliar. Essa escolha pelo fundo da sala era feita pela auxiliar de apoio, por acreditar que eles teriam mais espaço e não atrapalhariam os demais alunos.

\section{Sala 2}

A Sala 2 tinha 18 alunos matriculados. É importante ressaltar que, diferentemente da Sala 1, houve mudanças no quadro de profissionais ao longo da realização da pesquisa. 
http://dx.doi.org/10.5902/1984686X43296

No início das observações, havia uma professora regente que se interessou em participar da pesquisa e uma professora especializada. Entretanto, na segunda semana de observação, a professora especializada iniciou um período de três meses de licença e a professora regente pediu afastamento em decorrência de problemas de saúde. Na ocasião, a escola reorganizou-se para que outras professoras da instituição assumissem a turma naquele período. Passadas duas semanas, a Sala 2 teve sua estrutura reorganizada. Uma nova professora regente foi contratada e a docente que inicialmente atuava como regente, foi transferida para o cargo de professora especializada.

No primeiro mês de observação na Sala 2, o aluno diagnosticado com TGD/Autismo recebia o acompanhamento de uma auxiliar de apoio, que frequentemente chegava com atraso à escola. No segundo mês, como resultado de uma decisão da coordenação pedagógica da escola, houve uma mudança e o aluno passou a ser acompanhado por uma nova auxiliar. Ambas tinham formação de Ensino Médio completo. Em relação ao AEE, o aluno não frequentava o serviço em função da distância da sua casa até à escola. Como o AEE é ofertado no contraturno escolar, neste caso no período da manhã, sua mãe relatou às professoras que seria inviável acompanhá-lo à escola no turno matutino e depois retornar à tarde para a aula.

\section{Materiais}

Para o registro do cotidiano escolar, foi utilizado um diário de campo. Contabilizou-se o número de atividades endereçadas para toda a turma, diariamente, e para os alunos com TGD/Autismo, de modo específico. Foram analisadas as práticas educativas adotadas pelas professoras e auxiliares de apoio à inclusão com os alunos com TEA no cotidiano escolar. Para tanto, foram observados aspectos relacionados à interação dos alunos e com as profissionais; e estratégias e recursos utilizados para apresentar o conteúdo e as atividades aos alunos, incluindo a maneira como eram fornecidas as instruções e os suportes.

Quanto à interação, analisou-se como as professoras e as auxiliares de apoio relacionavam-se com os alunos, se estavam atentas aos seus interesses e particularidades, bem como à presença (ou não) de manifestação de vínculo estabelecido entre eles. Sobre estratégias e recursos disponíveis, foi observado como as profissionais apresentavam as atividades às crianças e os materiais utilizados. Considerou-se a existência (ou não) de suporte para a realização das tarefas e, no caso afirmativo, quais eram os tipos de ajuda 
http://dx.doi.org/10.5902/1984686X43296

oferecidos, adotando os seguintes critérios propostos por Hora (2018): com ajuda total (quando o adulto conduz fisicamente o aluno realizando todo o movimento com ele); parcial (quando o adulto conduz fisicamente o aluno realizando parte o movimento com ele) ou com independência.

Além disso, as propostas apresentadas aos alunos com autismo eram analisadas, verificando se eram comuns ou distintas do apresentado para a turma, se eram ou não planejadas.

Após as observações, foram feitas oito entrevistas com as profissionais da escola que tinham contato direto com os dois alunos, sendo seis professoras (duas regentes, duas especializadas e duas do AEE) e duas auxiliares de apoio à inclusão. Com permissão das profissionais, os depoimentos foram gravados e transcritos.

As entrevistas foram semiestruturadas o que favoreceu o surgimento de informações de forma mais livre, não condicionadas a uma padronização de alternativas. A entrevista teve um roteiro elaborado com questões básicas relacionadas ao tema da pesquisa, dentre as quais destacamos: Como é receber um aluno com autismo na sala de aula?; Como é o dia a dia em sala de aula?; Você tem conhecimento de estratégias que facilitem o aprendizado das crianças com autismo? Você utiliza algumas delas? Qual sua opinião sobre o trabalho do auxiliar? As perguntas eram complementadas durante a entrevista, conforme o desenvolvimento da interação do entrevistador e entrevistado. A entrevista semiestruturada proporciona flexibilidade e ampliação das questões, pois, à medida que as informações são fornecidas por meio do relato dos participantes, podem ser mais aprofundadas ou reconduzidas (MENDES; PASIAN; GONÇALVES, 2015).

Para analisar os dados das entrevistas, foi realizada uma análise de conteúdo. De acordo com Guerhardt, Ramos, Riquinho e Santos (2009), tal análise é uma técnica de pesquisa que preserva características metodológicas, como: objetividade, sistematização e inferência. Foi produzida, ainda, uma análise temática dos dados (GERHARDT; RAMO; RIQUINHO; SANTOS, 2009), a fim de verificar as afirmações apresentadas pelas entrevistadas sobre os assuntos abordados.

Por fim, foi aplicada a Escala CARS, com o intuito de compreender a percepção das professoras e das auxiliares sobre o aluno, visando captar as opiniões das profissionais sobre as características dos estudantes com TEA, por meio de um instrumento padronizado. 
A Escala foi desenvolvida por Schopler, Reichler e Renner (1988) e está dividida em 15 itens que auxiliam na identificação do autismo, distinguindo crianças com prejuízos do desenvolvimento sem autismo (PEREIRA, 2007).

O preenchimento das informações foi realizado pelas participantes com a pesquisadora, que esclareceu dúvidas expressas durante o processo.

\section{Resultado e discussão}

O objetivo dessa pesquisa foi descrever o processo de inclusão escolar de estudantes com TEA, matriculados no Ensino Fundamental na cidade de Belo Horizonte, a partir da análise das práticas educativas desenvolvidas pelos profissionais que têm contato direto com esses alunos. A pesquisa de campo englobou três momentos: i) a observação sistemática em sala de aula, ii) as entrevistas com as profissionais que atuam com os alunos com TEA e iii) a aplicação da Escala CARS.

\section{Sala 1}

As análises do diário de campo demonstram que a professora regente realizou, em média, 18 atividades por dia com a turma, distribuídas ao longo do período escolar, em atividades estruturadas dentro e fora da sala de aula: correção do Para Casa ou de atividades específicas das diferentes áreas (Português, Matemática, Ciências, História e Geografia); utilização de livros didáticos ou de material produzido para a turma; pausa para ir ao banheiro; realização de lanche no refeitório da escola; recreio na quadra aberta; repouso e, novamente, atividades estruturadas em classe.

Diariamente, a professora organizava a disposição dos alunos, com lugares predeterminados. Essa distribuição era marcada nas carteiras com uma ficha, contendo o nome de cada estudante. Entretanto, para o aluno Ricardo, em nenhum dia houve marcação, ficando a critério da auxiliar de apoio à inclusão organizar o espaço para ele sentar-se.

Durante quase todo o período de observação, o aluno e a auxiliar sentavam-se lado a lado, no fundo da sala. No Quadro 1, a seguir, é possível observar como, geralmente, era feita a organização do ambiente. A letra "A" representa os outros alunos da turma. 
http://dx.doi.org/10.5902/1984686X43296

Quadro 1 - Organização da Sala 1

\begin{tabular}{|c|c|c|c|c|c|}
\hline & $\begin{array}{c}\text { Mesa } \\
\text { Prof. }\end{array}$ & \multicolumn{2}{|c|}{ Quadro } & & Porta \\
\hline A & A & A & A & A & \\
\hline A & A & A & A & A & \\
\hline A & A & A & A & A & Pesquisadora \\
\hline Ricardo & AAl & A & A & A & \\
\hline
\end{tabular}

Fonte: Elaboração da própria da autora a partir da pesquisa de campo (2018).

É necessário refletir sobre este aspecto, pois o fato de Ricardo sentar sempre na última carteira da fila distanciava-o da professora, do quadro e do material apresentado à turma, como imagens, livros didáticos ou de literatura. Sua localização na sala dificultava, portanto, sua participação na proposta pedagógica, já que em muitos momentos distraíase e não conseguia manter a atenção no conteúdo apresentado. É provável que seu rendimento poderia melhorar, caso ele se sentasse mais próximo da professora, pois teria menos estímulos distratores e focaria mais a sua atenção no conteúdo apresentado pela regente (REIS, 2018; MOUSINHO, 2010). Além disso, o fato de a auxiliar permanecer sempre com Ricardo, sem mediar suas ações com a professora e colegas, indica sua condição de exterioridade em relação à turma. Verificou-se que, embora Ricardo pertencesse à mesma sala e ocupasse um espaço comum em relação aos colegas, ele ficava distante dos seus pares.

Quanto à organização da rotina diária, a professora utilizava a escrita com letras cursivas para registrar os combinados. Foi possível perceber que, muitas vezes, a rotina não cumpria o papel de dar previsibilidade e antecipar atividades diárias para os alunos, uma vez que a maior parte deles ainda não sabia ler. A mesma situação foi vivenciada pelo aluno com TEA, que apresentou dificuldades para compreender a sequência das atividades do dia, sendo frequentes os momentos em que a turma saía para o banheiro e ele confundia-se com o horário do recreio e/ou do refeitório. Nesse sentido, o apoio visual, como imagens das atividades ou fotos dos ambientes da escola, apresentado juntamente ao registro escrito, poderia constituir-se como alternativa para facilitar a compreensão dos alunos acerca da rotina. 
O estilo das aulas da professora regente consistia, em grande parte do tempo, no modelo de cunho expositivo, no qual a docente, localizando-se de frente para a turma e perto do quadro, dava instruções gerais para os alunos. A professora tinha o costume de oferecer suporte individualizado aos alunos de duas maneiras: chamando cada um por vez em sua mesa ou passando nas carteiras para conferir a atividade de cada criança. Para o aluno com TEA, foi possível perceber três formas mais preponderantes de relação da professora com ele: (i) endereçamento da instrução ou entrega da atividade diretamente para a auxiliar e não para o aluno, sendo que ele estava sentado ao lado dessa profissional; (ii) direcionamento da professora à mesa do aluno, conferência da atividade, com ausência de troca social, já que ela não fazia comentários ou elogios, tampouco conversava ou cumprimentava o aluno; (iii) momentos em que a professora dirigia-se diretamente a Ricardo, quando a auxiliar estava lanchando, e a professora procurava direcioná-lo para a atividade. Isso ocorreu, também, para chamar a atenção do aluno, pedindo que ele voltasse ao seu lugar ou que parasse de brincar com o colega.

Assim, a partir da sistematização dessas situações, foi possível verificar que, na maior parte dos momentos observados, houve ausência de direcionamento direto e de interação entre a professora e aluno. Em 36\% das oportunidades em que a professora trabalhou individualmente com a turma, ela não se dirigiu a Ricardo nem à auxiliar; e em $28 \%$ ela se dirigiu à auxiliar, mesmo que o aluno estivesse ao seu lado. Em outras palavras, em mais da metade das vezes (64\%) em que a professora trabalhava individualmente com os alunos da turma, com práticas individualizadas, ela não teve contato direto com Ricardo. A dificuldade em estabelecer uma relação educativa com Ricardo está presente, ainda, no discurso da professora Lílian, que destaca o desafio de prestar um serviço que atenda à toda a turma, dividindo sua atenção entre os 20 alunos.

Sobre as práticas educativas da professora especializada Cristiane, foram analisadas sua relação com Ricardo e as estratégias utilizadas para favorecer a participação do aluno nas tarefas do cotidiano escolar. A professora fazia uso de recursos musicais e materiais escolares diversos, além de extrapolar o ambiente da sala de aula, realizando atividades no pátio, na quadra e em outras áreas disponíveis na escola.

Um recurso muito utilizado durante as aulas de Ciências foi a música. Nos três dias em que a professora utilizou essa estratégia, Ricardo participou, cantando com a turma, e fazendo os gestos de acordo com o modelo apresentado pela professora, que se 
http://dx.doi.org/10.5902/1984686X43296

posicionava de frente para a turma. Ele demonstrou interesse nesse tipo de atividade, 0 que favoreceu sua participação na proposta.

A auxiliar de apoio à inclusão permanecia com o aluno durante quase todo o período escolar, desde o momento em que ele chegava à escola até a sua saída. Na sua interação com Ricardo, demonstrava ser atenciosa e carinhosa e, durante o período de observação, era perceptível o estabelecimento de vínculo entre os dois. Na sua prática cotidiana com o aluno, ela organizava para Ricardo as atividades que a professora ofertava para turma e Ihe oferecia diferentes maneiras de suporte. Em algumas ocasiões, foi possível observá-lo realizando as tarefas com ajuda total da auxiliar: em momentos em que Michele escrevia junto com o aluno o que era solicitado (mão sobre mão); momentos em que realizava a proposta da professora com ajuda parcial, ou seja, situações nas quais ela lhe dava dicas, como começar a escrever com o aluno para que ele finalizasse a proposta sozinho. Em outras situações, Ricardo realizava as atividades de forma independente, como na utilização do banheiro e nas brincadeiras durante o recreio. No tempo para repouso, Ricardo costumava seguir seus pares e esperar na sua mesa.

Uma nova situação verificada diz respeito aos momentos em que a auxiliar realizava atividades no lugar de Ricardo. Isso ocorria quando ela recortava e colava o Para Casa, os bilhetes na agenda, ou realizava algumas tarefas no caderno de Ricardo e quando organizava o material do aluno, desde o início da aula, buscando os livros e cadernos, até a finalização da aula, guardando os materiais na mochila e a levava até a saída. Movimentos como esses também foram presenciados em atividades de independência pessoal no refeitório. A auxiliar servia a refeição da escola na mesa do aluno e, dependendo do tipo de alimento, auxiliava-o a manusear a colher, levando-a até à boca. Depois, recolhia os utensílios sem que ele participasse ativamente, de alguma maneira, desse processo. Em dois episódios no refeitório, Ricardo demonstrou interesse no lanche de um colega e apontou para Michele, que se levantou, foi até o aluno e pediu o alimento para Ricardo. Essas situações do cotidiano escolar poderiam ter sido utilizadas como oportunidades de ensino para Ricardo, uma vez que Michele, como uma possível mediadora, poderia aproveitar para ensinar a Ricardo habilidades de comunicação e interação social, além de proporcionar-lhe oportunidade para desenvolver habilidades de resolução de problemas.

No Quadro 2, a seguir, destacam-se as situações vivenciadas na Sala 1: 
Quadro 2 - Atividades observadas na Sala 1

\begin{tabular}{lccccccc}
\hline $\begin{array}{c}\text { Dia de } \\
\text { observação }\end{array}$ & $\begin{array}{c}\text { Atividades } \\
\text { propostas } \\
\text { para a turma }\end{array}$ & $\begin{array}{c}\text { Atividades que } \\
\text { Ricardo fez } \\
\text { com } \\
\text { independência }\end{array}$ & $\begin{array}{c}\text { Ricardo } \\
\text { fez com } \\
\text { ajuda } \\
\text { total }\end{array}$ & $\begin{array}{c}\text { Ricardo } \\
\text { fez com } \\
\text { ajuda } \\
\text { parcial }\end{array}$ & $\begin{array}{c}\text { Ricardo } \\
\text { não } \\
\text { realizou } \\
\text { nenhuma } \\
\text { atividade }\end{array}$ & $\begin{array}{c}\text { Ricardo } \\
\text { realizou } \\
\text { algo } \\
\text { planejado }\end{array}$ & $\begin{array}{c}\text { Auxiliar } \\
\text { faz por } \\
\text { ele }\end{array}$ \\
\hline $\mathbf{0 5 / 0 3 / 2 0 1 8}$ & 18 & 5 & 1 & 2 & 9 & 1 & 7 \\
$\mathbf{0 9 / 0 3 / 2 0 1 8}$ & 25 & 7 & 5 & 2 & 11 & - & 7 \\
$\mathbf{1 2 / 0 3 / 2 0 1 8}$ & 29 & 5 & 10 & 5 & 9 & - & 2 \\
$\mathbf{0 2 / 0 4 / 2 0 1 8}$ & 11 & 2 & - & 1 & 6 & 2 & 2 \\
$\mathbf{0 3 / 0 4 / 2 0 1 8}$ & 18 & 6 & 2 & 2 & 5 & 3 & 2 \\
$\mathbf{0 4 / 0 4 / 2 0 1 8}$ & 19 & 2 & - & 3 & 14 & - & 3 \\
$\mathbf{0 9 / 0 4 / 2 0 1 8}$ & 19 & 3 & 3 & 6 & 6 & 1 & 4 \\
Total & 139 & 30 & 21 & 21 & 60 & 7 & 27 \\
\hline
\end{tabular}

Fonte: Dados coletados pela autora durante pesquisa de campo (2018).

Por meio desta sistematização, é possível observar que, em relação às atividades propostas para a turma, em apenas $21 \%$ das situações Ricardo realizou o mesmo que o grupo, com independência. Já em 30\% das propostas, ele participou com algum tipo de ajuda. Dois dados que chamam a atenção referem-se às atividades das quais ele não participou, representando $43 \%$ das oportunidades, além dos momentos em que a auxiliar realizou as tarefas por ele, totalizando $19 \%$.

Passaremos, então, à abordagem dos dados relativos à segunda sala investigada.

\section{Sala 2}

$\mathrm{Na}$ sala 2, foi possível perceber uma heterogeneidade marcante com alunos já alfabetizados e outros ainda em processo de alfabetização.

O aluno Túlio, com diagnóstico de TGD/Autismo, apresentou dificuldades de comunicação, que se restringia a poucas palavras, muitas vezes incompreensíveis.

Durante todos os dias de observação, os alunos da turma sentaram-se enfileirados, sendo que os lugares não eram preestabelecidos pelas professoras. O aluno com autismo e a auxiliar de apoio sentavam-se, nas últimas carteiras, lado a lado, como podemos ver no Quadro 3 a seguir: 
http://dx.doi.org/10.5902/1984686X43296

Quadro 3 - Mapeamento da Sala 2

\begin{tabular}{|c|c|c|c|c|}
\hline Porta & \multicolumn{3}{|c|}{ Quadro } & $\begin{array}{c}\text { Mesa } \\
\text { prof. }\end{array}$ \\
\hline A & A & A & A & A \\
\hline A & A & A & A & A \\
\hline A & A & A & A & A \\
\hline A & A & A & & \\
\hline & A & A & & \\
\hline Pesquisadora & & & AAl & Túlio \\
\hline
\end{tabular}

Fonte: Dados coletados pela autora durante pesquisa de campo (2018).

O fato de Túlio sentar-se no final da fila, ao lado da auxiliar, dificulta seu aprendizado, assim como apontado com Ricardo, na Sala 1. A distância da professora e dos materiais apresentados dificultava a concentração do estudante. Além disso, o fato de sentar-se um pouco mais distante dos pares, com a auxiliar ao lado, contribuía para a segregação de Túlio dentro do espaço comum. Essa situação foi verificada, também, no momento de ida ao refeitório e no recreio, quando Túlio sentava-se afastado das outras crianças, em outra mesa, junto a algumas auxiliares de apoio à inclusão e às crianças com deficiência por elas acompanhadas. Essas situações indicam um distanciamento em relação aos demais colegas, tanto no contexto da sala de aula, como no espaço externo, em relação aos outros estudantes.

As professoras, em geral, apresentavam os conteúdos de maneira expositiva, ficando de frente para a turma, lendo um livro de literatura ou realizando outra atividade estruturada. Foram comuns os exercícios de cópia do quadro e usando livros didáticos. A rotina da turma dividia-se em tarefas organizadas em classe, lanche no refeitório, recreio na quadra, repouso em sala.

Nas atividades apresentadas para a turma e para o aluno com autismo, foi possível observar que, apesar de ele permanecer dentro da sala a maior parte do tempo, havia uma ausência de práticas educativas que envolvessem o aluno no processo da turma, seja a partir do planejamento coletivo ou de uma proposta mais individualizada. Diante disso, o aluno acabou ficando ocioso e entediado, o que, provavelmente, motivou um comportamento frequente em sala - o de deitar-se no chão.

A primeira auxiliar que acompanhava o aluno ficava ao seu lado durante todo o tempo, porém com poucos momentos de interação e oportunidades de ensino. Sem oferecer-lhe 
atividades que pudessem contribuir para a sua participação nas propostas, permanecia, em geral, sentada do seu lado, muitas vezes manuseando seu aparelho celular. Nos momentos em que se dirigia ao aluno era para solicitar que ele se levantasse do chão e se sentasse na carteira ou para auxiliá-lo em situações de higiene pessoal.

Para analisar a média de atividades realizadas, por dia, na Sala 2, foram contabilizados os dados diários de observação e identificada uma média de 12 ações por dia, sendo que as propostas, em comparação à Sala 11, eram de atividades mais longas e detalhadas, fazendo com que os alunos passassem um tempo maior em cada tarefa.

Além das atividades planejadas para a turma, em dois dias de observação os alunos realizaram duas avaliações. Na primeira, a professora Lara entregou a prova para Túlio, que a folheou, mas não resolveu nenhuma questão. Lorena, a auxiliar que o acompanhava, não o direcionou para a prova e ficou, na maior parte do tempo, usando seu celular. O único momento em que se dirigiu a Túlio foi para lhe mostrar algumas figuras da avaliação. No período de realização da segunda avaliação, foi possível perceber uma diferença no desenvolvimento da atividade. Nesse dia, já havia ocorrido uma troca de auxiliar e quem o acompanhava era Vivian. A auxiliar apresentou para Túlio um exercício sobre o corpo humano para colorir, recortar e colar, enquanto os alunos realizavam a avaliação com a professora.

Foi possível perceber que a troca de auxiliar contribuiu para que o aluno passasse menos tempo ocioso em sala e com mais propostas pedagógicas. Porém, mesmo assim, na maior parte do tempo, as atividades oferecidas para Túlio não tinham relação com as propostas desenvolvidas pelos pares. Esta situação coloca em evidência as dificuldades que as auxiliares de apoio enfrentam e leva-nos a refletir que tais sujeitos poderiam beneficiar-se de processos de formação continuada, bem como de maior orientação dos professores e da equipe pedagógica das escolas, já que não são pessoas com formação no Magistério. Além disso, o fato de a legislação não definir a formação necessária para esta atuação complexifica ainda mais a questão.

Em relação a não participação de Túlio nas avaliações, Mousinho et al (2010) salientam a importância da flexibilização do currículo, das avaliações e do modelo de ensino. De acordo com as autoras, "para ensinar na diversidade, a flexibilização se torna uma máxima" (MOUSINHO et al, 2010, p. 102). Portanto, adaptar as atividades propostas para a turma, assim como as avaliações, seja em relação ao conteúdo, à formatação ou à quantidade de exercícios, é uma tarefa da equipe escolar. 
Ao retomar as análises sobre a participação do aluno nas propostas direcionadas para toda a turma, foram contabilizadas as atividades que ele realizou com independência, quantas foram planificadas especificamente para o aluno, o número das que não foram planejadas e também os momentos em que nenhuma tarefa foi feita, ou seja, nos quais Túlio ficou sem realizar propostas pedagógicas em classe. Essa distribuição pode ser verificada no Quadro 4:

Quadro 4 - Atividades propostas na Sala 2

\begin{tabular}{cc|cccc}
\hline DIA & $\begin{array}{c}\text { Total de } \\
\text { atividades } \\
\text { propostas }\end{array}$ & $\begin{array}{c}\text { Realizou } \\
\text { atividades } \\
\text { planejadas }\end{array}$ & $\begin{array}{c}\text { Realizou } \\
\text { atividades } \\
\text { não } \\
\text { planejadas }\end{array}$ & $\begin{array}{c}\text { Realizou o } \\
\text { mesmo que a } \\
\text { turma, com } \\
\text { independência }\end{array}$ & $\begin{array}{c}\text { Não realizou } \\
\text { nenhuma } \\
\text { atividade }\end{array}$ \\
\hline $\mathbf{1 0 / 0 4 / 2 0 1 8}$ & 15 & 0 & 0 & 4 & 10 \\
$\mathbf{1 6 / 0 4 / 2 0 1 8}$ & 14 & 0 & 4 & 2 & 6 \\
$\mathbf{0 4 / 0 5 / 2 0 1 8}$ & 17 & 1 & 2 & 2 & 2 \\
\hline $\mathbf{1 1 / 0 5 / 2 0 1 8}$ & 11 & 4 & 0 & 2 & 2 \\
$\mathbf{1 8 / 0 5 / 2 0 1 8}$ & 9 & 8 & 3 & 2 & 1 \\
$\mathbf{2 4 / 0 5 / 2 0 1 8}$ & 9 & 2 & 0 & 3 & 1 \\
$\mathbf{0 4 / 0 6 / 2 0 1 8}$ & 12 & 3 & 0 & 2 & 4 \\
$\mathbf{0 6 / 0 6 / 2 0 1 8}$ & 10 & 1 & 0 & 2 & 2 \\
Total & 97 & 19 & 9 & 19 & 28 \\
\hline
\end{tabular}

Fonte: Dados coletados pela autora durante pesquisa de campo (2018).

Enquanto Túlio realizou um total de 47 atividades, seus pares realizaram um pouco mais que o dobro (97), durante o mesmo período. Outro ponto relevante é em relação ao aumento de ações planejadas o tempo ocioso em sala. Possivelmente, o aumento das atividades planejadas e a diminuição do tempo ocioso decorrem da mudança da auxiliar de apoio à inclusão, quem planejava e organizava tais atividades.

Foi possível verificar uma prática da professora especializada que ganhou destaque: a docente propôs para a turma um exercício de Artes e levou o mesmo material para o aluno com TEA, porém com tamanho maior, para facilitar o manejo e permitir que ele realizasse a mesma proposta que a turma.

Ao atender às necessidades de Túlio, flexibilizando as ações e materiais com o intuito de proporcionar o acesso e a participação do aluno à proposta, essa atitude pode ser considerada como um exemplo de uma prática educativa inclusiva (RODRIGUES, 2013). Entretanto, é importante assinalar que, ao longo da pesquisa de campo, foram observadas 
poucas situações semelhantes, o que permite indicar que essas práticas foram pontuais no cotidiano do aluno, durante todo o período da pesquisa.

\section{Escala CARS}

Como já dito, as profissionais preencheram a Escala CARS durante o desenvolvimento da pesquisa. Cabe ressaltar que, para realizar um diagnóstico de autismo, não é suficiente aplicar somente esta Escala, porém "ela pode indicar com segurança se uma criança apresenta um conjunto de sintomas característicos de autismo ou não" (GOMES; MENDES, 2010, p. 391). A seguir, no Quadro 5, são apresentados os resultados da avaliação:

Quadro 5 - Resultados da Escala CARS

\begin{tabular}{cccc}
\hline Profissional & Sala/Aluno & Pontuação & Resultado na Escala CARS \\
\hline Lílian & 01/ Ricardo & 24 & Sem autismo \\
Michele & 01/ Ricardo & 38 & Autismo Grave \\
Marina & 02/ Túlio & 44 & Autismo Grave \\
Vivian & 02/ Túlio & 50 & Autismo Grave \\
\hline
\end{tabular}

Fonte: Dados coletados pela autora durante pesquisa de campo (2018).

Em relação ao aluno Ricardo, verificamos uma acentuada diferença entre as pontuações dadas pela professora Lílian e pela auxiliar Michele. Segundo a pontuação de Lílian, Ricardo não obtém o mínimo de pontos referentes ao autismo (24 pontos). Já na avaliação de Michele, ele obteve um resultado de autismo grave, com uma quantificação acima de 37. Essa discrepância entre os números pode indicar falta de clareza e imprecisão na avaliação da professora sobre os comportamentos de Ricardo. Como apresentado na análise das observações da Sala 1, durante o desenvolvimento de sua prática com a turma, Lílian demonstrou pouca atenção ao aluno, aos seus interesses e comportamentos e Ricardo passava a maior parte do tempo com Michele. Assim, considera-se a análise de Michele mais apropriada, visto que ela o observava por mais tempo o aluno e suas considerações aproximam-se mais das características que ele apresentava, como capacidade de comunicar, ainda que restrita, presença de uma agitação motora e de estereotipias, interesse em brincar no momento do recreio, mas com muita dificuldade de iniciar interação com os pares.

$\mathrm{Na}$ sala 2, os resultados da pontuação dada pela professora e auxiliar aproximaramse mais. Nas respostas da professora Marina, Túlio obteve uma pontuação de 44, o que indica um quadro de autismo grave, e na de Vivian, a pontuação foi de 50, o que mantém 
o mesmo quadro. Pode-se dizer que a percepção das duas profissionais em relação aos comportamentos e habilidades de Túlio, ainda que com algumas diferenças, está mais próxima do que das profissionais da Sala 1.

Os resultados referentes à pontuação de Túlio estão de acordo com o que foi percebido durante o período de observação da Sala 2, pois o aluno apresenta dificuldades consistentes em diversos âmbitos, como das relações pessoais, da imitação, de respostas emocionais e do uso de objetos. Ainda que com a troca de auxiliar tenha sido possível identificar mudanças no seu comportamento, como diminuição da agressividade e dos gritos, ele ainda apresentava as características em determinadas situações.

\section{Análise das entrevistas: 0 olhar dos profissionais para o autismo e a inclusão}

Após as observações, foram realizadas entrevistas com duas professoras regentes, duas especialistas e duas auxiliares do AEE, além das duas pessoas de apoio à inclusão, num total de oito entrevistas. A amostra, ainda que pequena, é significativa, pelo seu caráter qualitativo. Na análise das entrevistas, foram identificadas quatro categorias: o (Des)conhecimento sobre o TEA; Papel do auxiliar de apoio à inclusão; Atendimento Educacional Especializado no contexto da escola; Desafios da inclusão.

$\mathrm{Na}$ categoria "(Des)conhecimento sobre o TEA", identificou-se a tendência das profissionais em considerar o TEA como uma dificuldade marcante de interação com os colegas e na socialização, o que, de acordo com a definição do DSM-5, é uma característica do Transtorno. Porém, o sentimento de incerteza está presente no discurso dessas profissionais, que possuem muitas dúvidas relacionadas à etiologia e às práticas educativas, que contribuiriam para a aprendizagem do aluno. Esses apontamentos estão em consonância aos estudos sobre o tema, que indicam um despreparo dos professores para o trabalho educativo com alunos com TEA. Os docentes demonstram pouca informação e formação sobre o Transtorno, e apresentam lacunas quanto ao uso de estratégias e recursos adequados para a inclusão dos alunos diagnosticados com TEA (GOMES; MENDES, 2010; FAVORETO; LAMÔNICA; 2014; LIMA; LAPLANE, 2016; RIBEIRO; MELO; SELA 2017).

O desconhecimento traz consequências diretas para a atuação com estes alunos, pois, para intervir, criar recursos e estabelecer práticas educativas que promovam a aprendizagem dos alunos com TEA, na perspectiva inclusiva, é fundamental que os 
http://dx.doi.org/10.5902/1984686X43296

profissionais da educação tenham conhecimento sobre o assunto, possam construir uma prática inclusiva e esclareçam mitos e dúvidas.

Na segunda categoria "Papel da auxiliar de apoio à inclusão", o trabalho desenvolvido pelas auxiliares emergiu como um serviço questionável para as professoras e desafiador para as próprias auxiliares, que reconheceram algumas limitações no exercício de sua função e teceram críticas, como a falta de conexão entre o que se ensina para a turma e o que se trabalha com o aluno acompanhado. Na perspectiva das professoras regentes, foi identificado um sentimento de alívio e de reconhecimento sobre a importância de ter a auxiliar de apoio, na classe, acompanhando os alunos com deficiência. Todavia, foram apresentadas muitas críticas em relação à formação e às condições de trabalho, como a carga horária exaustiva dessas profissionais.

$\mathrm{Na}$ terceira categoria "Atendimento Educacional Especializado no contexto da escola", as professoras reconhecem a importância do atendimento para as crianças com deficiência e ressaltam a necessidade de um alinhamento entre as propostas do AEE e as expectativas das famílias. Porém, identificam uma série de limitações, como a reduzida quantidade de salas disponíveis diante da demanda e a sobrecarga de trabalho. Em relação a esse último ponto, elas relataram que são responsáveis pela produção de materiais adaptados, pelo acompanhamento de um grande número de alunos com deficiência e precisam enfrentar a falta de disponibilidade ou abertura dos profissionais de outras instituições para recebê-las.

Por último, na categoria "Desafios da inclusão", as profissionais, ao analisarem o processo de inclusão na Rede Municipal de Ensino, reconhecem o avanço em termos de acesso, pois percebem que alunos com deficiência têm chegado cada vez mais à escola regular. Entretanto, as profissionais manifestaram um sentimento de insegurança e insatisfação com a situação que vivenciam. Das oito profissionais entrevistadas, cinco definiram a chegada de um aluno com autismo na sala de aula (e na escola como um todo) como desafiador. Sentimento de insegurança e medo estão presentes no discurso destas professoras, que também relataram, como fatores desafiadores, a dificuldade de estabelecer trabalho interdisciplinar com o $\mathrm{AEE}$, a relação com as auxiliares de apoio à inclusão e a pouca oferta de formações. As entrevistadas expressaram a sua visão de que esses elementos prejudicavam o conhecimento sobre a condição vivida pelos alunos. 
http://dx.doi.org/10.5902/1984686X43296

\section{Conclusão}

A inclusão dos alunos com deficiência na escola regular é um processo em construção. Nesse sentido, esta pesquisa indica avanços tanto em uma esfera macro, que diz respeito ao direito à escolarização, assegurado pela legislação nos últimos anos, inclusive destacando o serviço do Atendimento Educacional Especializado, quanto em uma esfera micro, que se refere a atitudes e crenças das profissionais que atuam na escola. Todas as profissionais entrevistadas reconhecem a importância da educação deste público. Embora o estudo tenha delimitado a investigação de práticas educativas em duas salas, possibilitou identificar a presença de práticas orientadas por uma perspectiva inclusiva, mesmo que com baixa frequência.

O estudo confirmou que o processo de inclusão ainda é visto pelas professoras como um desafio e o fato de receber um aluno com autismo gera um sentimento de insegurança e angústia, pois, muitas vezes, as profissionais não sabem como atuar e, ao mesmo tempo, conciliar a atenção dirigida a todos os alunos da sala e ao estudante com TEA. Esse resultado aproxima-se dos estudos de Azevedo e Nunes (2018) e de Nascimento, Cruz e Braun (2016).

A precária formação das auxiliares de apoio à inclusão e a baixa oferta de processos formativos relacionados à sua atuação são retratados pelas professoras como lacunas no processo de inclusão. As auxiliares relatam, ainda, haverá falta de orientação sistemática para a efetivação da inclusão escolar, o que faz emergir um sentimento de solidão durante a realização das ações de acompanhamento na escola.

Esta pesquisa indica, todavia, que os alunos têm passado a maior parte do tempo dentro de sala, o que pode ser considerado um avanço, ao se analisar o processo de inclusão escolar dos alunos com TEA. Gomes e Mendes (2010) investigaram a situação de 33 alunos com autismo na Rede Municipal de Ensino de Belo Horizonte e identificaram que os alunos do $1^{\circ}$ ciclo permaneciam em sala "às vezes" - o que diminuía ainda mais as chances de aprendizagem desses alunos. É necessário assinalar que o número de matrícula dos alunos com TEA na escola comum aumentou significativamente nos últimos anos (SANTOS; ELIAS, 2018), o que indica a ampliação da presença deste público na escola. Entretanto, assegurar somente a presença, oferecendo um serviço assistencialista que não visa à promoção da aprendizagem de conteúdos pedagógicos e à promoção da autonomia, pautado apenas na perspectiva do cuidado, pode significar que uma educação para todos não está sendo efetivamente oferecida. Assim, é fundamental articular as 
http://dx.doi.org/10.5902/1984686X43296

diferentes ações educativas desenvolvidas no interior da escola, promover espaços de formação continuada que atendam às especificidades dos diversos profissionais envolvidos e desenvolver ações, no âmbito do município, que permitam o acompanhamento dos processos de inclusão escolar. Tais fatores mostram-se essenciais para a construção de práticas educativas que se alinhem ao direito à educação.

\section{Referências}

AMERICAN PSYCHIATRIC ASSOCIATION. Manual diagnóstico e estatístico de transtornos mentais. 5a. Ed. Porto Alegre: Artes Médicas, 2014.

AZEVEDO, Mariana Queiroz Orrico; NUNES, Débora Regina de Paula. Que sugerem as pesquisas sobre Métodos de Ensino para alunos com Transtorno do Espectro Autista? Uma revisão integrativa de literatura. Arquivos analíticos de políticas educativas, Vol. 26, n. 24, pp. 1-24, 2018.

BRASIL. Congresso Nacional. Lei de Diretrizes e Bases da Educação Nacional. Lei no 9493, de 20 de dezembro de 1196. Brasília/DF: Diário Oficial da União de 23 de dezembro 1996.

BRASIL. Ministério da Educação, Secretaria de Educação Especial. Política Nacional de Educação Especial na Perspectiva da Educação Inclusiva. Brasília/ DF, 2008.

BRASIL. Presidência da República. Casa Civil. Política Nacional de Proteção dos Direitos da Pessoa com Transtorno do Espectro Autista. Lei no 12.764, de 11 de dezembro 2012, Brasília/DF, 2012.

BRASIL. Presidência de República. Secretaria Geral. Lei Brasileira de Inclusão da Pessoa com Deficiência (Estatuto da Pessoa com Deficiência), Lei oㅡ 13.146, de 6 de julho 2015, Brasília/DF, DOU, 2015.

BRASIL. Instituto Nacional de Estudos e Pesquisas Educacionais Anísio Teixeira. Censo Escolar, 2017. Disponível em: www.portal.mec.gov.br. Acesso em: 03 set. 2019.

CABRAL, Cristiane S; MARIN, Ângela Helena. Inclusão escolar de crianças com transtorno do espectro autista: uma revisão sistemática da literatura. Belo Horizonte: Educação em Revista.v. 33, pp. 01-30, 2017.

CENTER FOR DISEASE CONTROL AND PREVENTION. CDC: Saving Lives, Protecting People. Disponível em https://www.cdc.gov/ncbddd/autism/data.htmlhttps://www.cdc.gov/ncbddd/autism/data.html Acesso em: 29 mar. 2020.

DONVAN, John; ZUCKER, Caren. Outra Sintonia: A história do Autismo. São Paulo: Companhia das Letras, 2017. 
FAVORETTO, Natália Caroline; LAMÔNICA, Dionísia Aparecida C. Conhecimento e Necessidades dos professores em relação aos transtornos do espectro autístico. Revista Brasileira de Educação Especial, Marília, v. 20, n.1, pp. 103-116, 2014.

GOMES, Camila Graciella Santos, MENDES, Enicéia G. Escolarização inclusiva de alunos com autismo na rede municipal de ensino de Belo Horizonte. Revista Brasileira de Educação Especial, Marília, v.16 n.3, pp.375-396, 2010.

GERHARDT, Tatiana E. et al. Estrutura do projeto de pesquisa. In: GERHARDT, Tatian Engel; SILVEIRA, Denise Tolfo (Orgs) Métodos de Pesquisa. Porto Alegre: Editora da UFRGS, 2009.

HORA, Cássia L. Procedimentos de dicas e correções de erros: para que servem e como utilizar? In: DUARTE; Cintia; SILVA; Luciana; VELLOSO; Renata. Estratégias da Análise do Comportamento Aplicada para pessoas com Transtornos do Espectro do Autismo. São Paulo: Memnon Edições Científicas, 2018.

KAUARK; Fabiana da Silva; MANHÃES; Fernanda Castro; MEDEIROS; Carlos Henrique. Metodologia da Pesquisa: um guia prático. Itabuna: Via Litterarum 2010.

LIMA, Stéfanie M.; LAPLANE, Adriana Lia F. Escolarização de Alunos com Autismo. Revista Brasileira de Educação Especial, Marília, v. 22, n. 2, pp. 269-284, 2016.

MANZINI, Eduardo José. Entrevista semi-estruturada: análise de objetivos e de roteiros. SEMINÁRIO INTERNACIONAL SOBRE PESQUISA E ESTUDOS QUALITATIVOS. Bauru, 2004.

MENDES, Enicéia G. A radicalização do debate sobre inclusão escolar no Brasil. Revista Brasileira de Educação, Rio de Janeiro, v. 11, n. 33, pp. 387-405, set/dez, 2006.

MENDES, Enicéia G.; PASIAN, Maria Sílvia; GONÇALVES, Adriana G. Pesquisa qualitativa em educação especial. In: COSTAS, A. T. C.; Pavão, S. M. O. (Org.).

Pesquisa qualitativa em educação especial. 1ed., v. 1, pp. 123-146, 2015.

MOUSINHO, Renata et al. Mediação Escolar e Inclusão: revisão, dicas e reflexões. Revista Psicopedagogia, Rio de Janeiro, v. 27, n. 82, pp. 92-108, 2010.

NASCIMENTO, Fabiana Ferreira; CRUZ, Mara Monteiro; BRAUN, Patrícia. Escolarização de Pessoas com Transtorno do Espectro do Autismo a partir da Análise da Produção Científica Disponível na SciELO Brasil (2005 - 2015). Arquivos Analíticos de Políticas Educativas, Vol. 25, n. 125, pp. 1- 29. 2016.

NUNES, Débora Regina; AZEVEDO, Mariana Queiroz; SCHMIDT, Carlo. Inclusão educacional de pessoas com Autismo no Brasil: uma revisão da literatura. Revista Educação Especial, vol 26, n.47, pp 557 - 572. 2013.

ORGANIZAÇÃO MUNDIAL DE SAÚDE. Classificação de Transtornos Mentais e de Comportamento da CID-10: descrições clínicas e diretrizes diagnósticas. Porto Alegre: Artes Médicas, 1993. 
PAULA, Cristiane S et al. Brief report: Prevalence of pervasive developmental disorder in Brazil: A pilot study. Journal of Autism and Developmental Disorders, v. 12, pp. 17381742, 2011.

PEREIRA, Alessandra; RIESGO, Rudimar; WAGNER, Mário. Autismo infantil: tradução e validação da escala Childhood Autism Rating Scale para o uso no Brasil. Jornal de Pediatria, Rio de Janeiro, v. 86, n. 6, 2008.

REIS, Patrícia Ferreira. A comunicação da criança com transtorno do espectro do autismo (TEA). In: BORGES, Adriana Araújo; NOGUEIRA, Maria Luisa Magalhães. 0 aluno com autismo na escola. Campinas: Mercado das Letras, 2018, cap. 4, pp. 111-137.

RIBEIRO, Daniela M.; MELO, Ninive R.; SELLA, Ana Carolina. A inclusão de estudantes com autismo na rede municipal de ensino de Maceió. Revista de Educação Especial, Santa Maria/RS, v. 30, n.58, p.425-440, 2017. Disponível em:

https://periodicos.ufsm.br/educacaoespecial/article/view/25264 Acesso em: 05 jan. 2020.

RODRIGUES, Sônia Maria. A construção de práticas pedagógicas inclusivas em uma escola pública de Belo Horizonte, 2013. 266 p. Tese (Doutorado em Educação) Universidade Federal de Minas Gerais, Faculdade de Educação, Belo Horizonte, 2013.

SANTOS, Vivian; ELIAS, Nassim Chamel. Caracterização das Matrículas dos Alunos com Transtorno do Espectro do Autismo por Regiões Brasileiras. Revista Brasileira de Educação Especial, Santa Maria/RS, v.24, n.4, p.465-482, 2018.

SCHMIDT, Carlo. Transtorno do Espectro Autista: Onde estamos para onde vamos.

Psicologia em Estudo, Maringá, v. 22, n. 2, pp. 221-230, abri/jun. 2017. Disponível em: http://periodicos.uem.br/ojs/index.php/PsicolEstud/article/view/34651/pdf Acesso em: 03 jan. 2020.

SCHOPLER, Eric; REICHLER, Robert Jay; RENNER, Barbara R. The Childhood Autism Rating Scale (CARS) for Diagnostic Screening and Classification of Autism, Western Psychological Services, Los Angeles, Calif, USA, 1988.

ZANATTA, Joana; MARCON, Vera Inês; MARASCHIN; Maria Lucia Marocco. O processo de transição da educação infantil para os anos iniciais do ensino fundamental: Desafios e possibilidades. In: XII CONGRESSO NACIONAL DE EDUCAÇÃO, 2015.

\section{Correspondência}

Luiza Pinheiro Leão Vicari - Vínculo Desenvolvimento Infantil, Rua Romualdo Lopes Cançado, Castelo, Belo Horizonte, Minas Gerais - Brasil

CEP: $30840-460$

\section{(i) (8)}

This work is licensed under a Creative Commons Attribution-NonCommercial 4.0 International (CC BY-NC 4.0) 